\title{
Synthesis of ZnO Nanostructures \\ Using Sublimation-Condensation and Sol-Gel Methods: Evaluation of the Photocatalytic Degradation Activity of Industrial Dye
}

\author{
S. Harouni, N. Bouanimba* and N. Boulares \\ Laboratoire de Physique-chimie des semiconducteurs (LPCS), Département de Physique, \\ Faculté des Sciences Exactes, Université des Frères Mentouri Constantine, Algeria \\ (Received February 5, 2019; revised version April 1, 2019; in final form April 9 2019)
}

\begin{abstract}
$\mathrm{ZnO}$ nanostructures were prepared by sublimation-condensation (ZnO-SPVD) technique and sol-gel method (ZnO-SG). The produced materials were used in a photocatalytic degradation of a pollutant (gentian violet) at different operational conditions. The materials were characterized by X-ray diffraction (XRD) and Raman spectra techniques (RS). The obtained results indicated that the photocatalytic activity was correlated to the particle sizes of catalysts. The catalyst prepared by the physical method (ZnO-SPVD) exhibited a higher photoactivity to degrade GV dye than the catalyst prepared by the chemical method (ZnO-SG). In the presence of each of ZnO-SPVD or $\mathrm{ZnO}-\mathrm{SG}$, the experiments were carried out to investigate the factors that influence the photocatalytic degradation of GV, such as the adsorption amount, $\mathrm{pH}$ of dye solution, electron acceptors $\left(\mathrm{H}_{2} \mathrm{O}_{2}\right)$, and presence of inorganic species commonly present in real wastewaters $\left(\mathrm{HCO}_{3}^{-}\right)$. The experimental results showed that adsorption on the surface of both samples was an important parameter controlling the photocatalytic activity. For both catalysts, the degradation rate in alkaline medium was higher than that in natural and acidic one. The presence of the $\mathrm{H}_{2} \mathrm{O}_{2}$ and $\mathrm{HCO}_{3}^{-}$ions increased the effectiveness of the photodegradation.
\end{abstract}

DOI: 10.12693/APhysPolA.136.424

PACS/topics: Zn, sol-gel method, sublimation-condensation technique, adsorption, photocatalytic degradatio, dye

\section{Introduction}

Zinc oxide is a very important material in some technological applications. It is commonly found in nature and can also be easily synthesized in the laboratory. It is widely used in catalysis, sensors, ceramics, and optoelectronic devices, due to its excellent optical, peizoelectrical, and magnetic properties $[1,2]$.

In recent years, the photocatalytic properties of $\mathrm{ZnO}$ were also extensively studied [3-6]. Owing to the rapid photoresponse and good photoelectric conversion properties, $\mathrm{ZnO}$ exhibits high photocatalytic efficiencies on decomposing organic pollutants in water. Additionally, unlike other semiconductors, $\mathrm{ZnO}$ is nontoxic, low cost, and suitable to work using sunlight as energy source, which make it an ideal candidate for practical applications on environmental treatments.

Many methods for the production of $\mathrm{ZnO}$ nanostructures have been described in the literature such as chemical or physical vapor deposition (CVD or PVD) [7, 8], sol-gel (SG) [9], hydrothermal [10], and precipitation methods [11], resulting in $\mathrm{ZnO}$ nanoparticles with a nanometric size.

In recent years advanced oxidation processes (AOPs) have been developed to meet the increasing need of

*corresponding author; e-mail: nourbouanimba@gmail.com an effective wastewater treatment. Heterogeneous photocatalysis, one of the AOPs, is a cost-effective treatment method for the removal of toxic pollutants from wastewater sowing to its ability to convert these pollutants into $\mathrm{CO}_{2}, \mathrm{H}_{2} \mathrm{O}$, and mineral acids [12-14]. Synthetic dyes constitute one of the larger groups of pollutants in wastewater released from textile, leather tanning, paper production, plastics, and other industries. These dyes have a big impact on the environment because of their potential carcinogenic properties $[15,16]$.

In the photocatalytic process, semiconductor particles are irradiated with light energy equal to or greater than its band gap. It results in the formation of electronhole pair. Electron $\left(e^{-}\right)$is present in conduction band, whereas hole $\left(h^{+}\right)$is present in the valence band. The detailed mechanism of the photocatalytic process has been discussed extensively in the literature [12-14].

In this paper, highly crystalline $\mathrm{ZnO}$ nanoparticles were synthesized by sublimation-condensation technique (ZnO-SPVD) and sol-gel method (ZnO-SG), and characterized by X-ray diffraction (XRD) and Raman spectra techniques (RS).

The study of the efficiency of the two series of zinc oxide samples was carried by the investigation of the photocatalytic activity by performing the decomposition of Gentian violet $(\mathrm{GV})$ dye, a cationic triphenylmethane dye under UV illumination over each of the two synthesized catalysts. 
The investigated dye (Gentian violet) is extensively used in the textile, paper, and many industries. Gentian violet is hazardous compound and suspected to be toxic and carcinogenic for humans and animals [17, 18]. The efficiency of the GV photocatalytic degradation reaction was studied under different experimental conditions, the influence of several experimental parameters, such as the adsorption of dye onto $\mathrm{ZnO}$ surface, the initial dye concentration, the initial $\mathrm{pH}$, the addition of $\mathrm{HCO}_{3}^{-}$ion and the addition of hydrogen peroxide, upon the GV degradation rate constant was also investigated.

\section{Materials and experimental methods}

\subsection{Reagents and chemicals}

Gentian violet (GV, Biochem chemopharma, C.I: 42.555 , molecular formula: $\mathrm{C}_{25} \mathrm{H}_{30} \mathrm{~N}_{3} \mathrm{Cl}$, molecular weight $\left.=407.979 \mathrm{~g} \mathrm{~mol} \mathrm{~L}^{-1}\right)$. The structure of $\mathrm{GV}$ is presented in Fig. 1. $\mathrm{H}_{2} \mathrm{SO}_{4}$ (98\%, Merck) and $\mathrm{NaOH}$ (Carlo Erba) for $\mathrm{pH}$ adjustments. $\mathrm{NaCl}$ and $\mathrm{HaHCO}_{3}$ (Prolabo), $\mathrm{H}_{2} \mathrm{O}_{2}$ (Labosi). All solutions were prepared with deionized ultrapure water from a Milli pure water (Milli-Q purification unit).

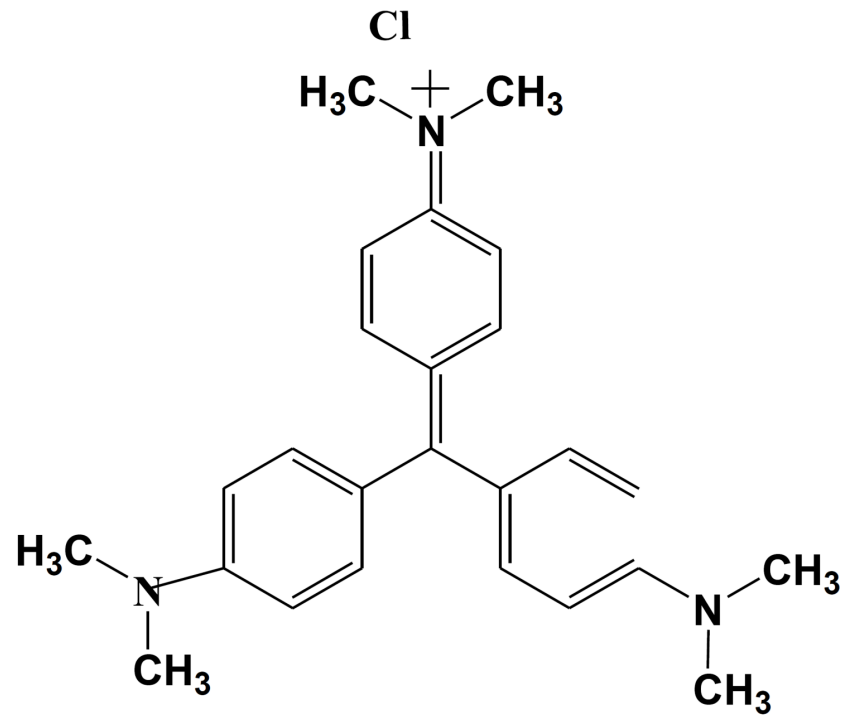

Fig. 1. Molecular structure of Gentian Violet (GV).

Sol-gel method: Nanoparticles of Zinc oxide were prepared by the sol-gel (citrate route) method using zinc acetate, $\mathrm{ZnC}_{4} \mathrm{H}_{6} \mathrm{O}_{4}$ (Panreac), as the starting materials. Citric acid $\mathrm{C}_{6} \mathrm{H}_{8} \mathrm{O}_{7} \cdot \mathrm{H}_{2} \mathrm{O}$ (Panreac) was used as a complexing agent.

The sublimation-condensation technique: Nanoparticles of Zinc oxide were prepared by the sublimation-condensation under 660 Torr air pressure, in a solar reactor placed at the focus of a parabolic concentrator. The nanopowders were deposited on the spherical surface of a glass balloon [19].

\subsection{Characterization of catalysts}

\subsubsection{Xray diffractometry (XRD):}

To determine the phase composition and to estimate the mean crystallite size, powder X-ray diffraction (XRD) patterns were recorded for synthesized samples using PANalytical X'Pert Pro Philips X-ray diffractometer with $\mathrm{CuK}_{\alpha}$ radiation, $\left(\lambda_{\mathrm{Cu}}=1.5418 \AA\right)$ and the accelerating voltage and current were $40 \mathrm{kV}$ and $40 \mathrm{~mA}$, respectively.

The XRD spectra of the obtained nanoparticles are shown in Fig. 2. The peaks appearing at $2 \theta$ range of $31^{\circ} \mathrm{C}, 34^{\circ} \mathrm{C}, 36{ }^{\circ} \mathrm{C}, 47^{\circ} \mathrm{C}, 56{ }^{\circ} \mathrm{C}$, and $63^{\circ} \mathrm{C}$ correspond respectively to (100), (002), (101), (102), (110), and (103) peaks of hexagonal wurtzite polycrystalline ZnO structure (JCPDS card No. 00-036-1451).

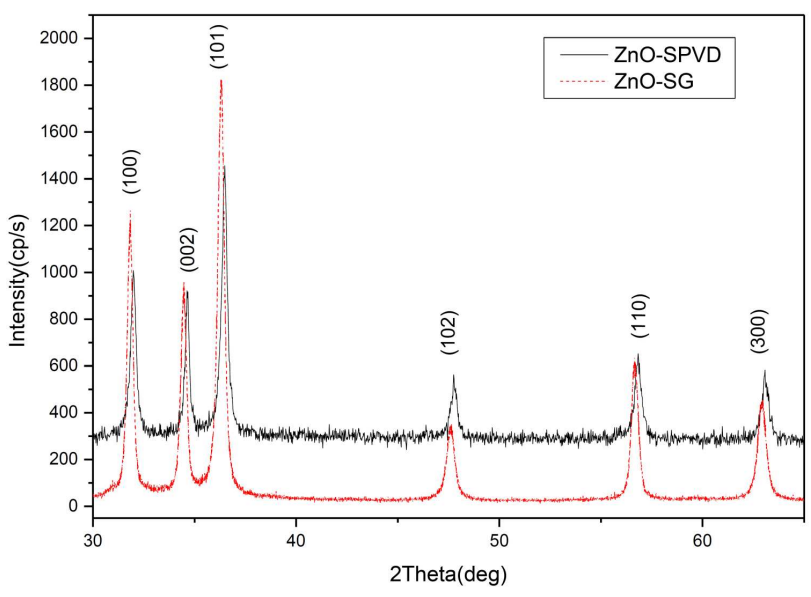

Fig. 2. XRD spectra of ZnO-SPVD and $\mathrm{ZnO}-\mathrm{SG}$ catalysts.

Crystallite size was obtained by Debye-Scherrer formula given by equation $[16,20]$ :

$$
D=K \frac{\lambda}{\beta \cos \theta},
$$

where $D$ is the crystallite size (in nm), 0.94 is the particle shape factor which depends on the shape of the particles (the typical value is 0.94 ), $\lambda$ is the $\mathrm{CuK}_{\alpha}$ radiations $(1.5418 \AA), \beta$ is full width at half maximum (FWHM) of the selected diffraction peak at angle $36^{\circ} \mathrm{C}$ corresponding to (101) plane and $\theta$ is the Bragg angle obtained from $2 \theta$ value corresponding to maximum intensity peak in XRD pattern. The mean crystallite size obtained using this formula was $36 \mathrm{~nm}$ for sol-gel derived particles and $26 \mathrm{~nm}$ in case of sublimation-condensation technique. In addition, the specific surface are calculated by the Gauss model was found to be $737.7 \mathrm{~m}^{2} \mathrm{~g}^{-1}$ and $759.3 \mathrm{~m}^{2} \mathrm{~g}^{-1}$ for ZnO-SPVD and ZnO-SG, respectively.

\subsubsection{Raman spectra:}

The Raman spectrum (RS) for the two catalysts samples was collected with a Bruker Senterra Dispersive Raman microscope spectrometer using $532 \mathrm{~nm}$ excitation from a $3 \mathrm{~B}$ diode laser having $3 \mathrm{~cm}^{-1}$ resolution 
in the spectral region of $3700-45 \mathrm{~cm}^{-1}$. The Raman spectra of $\mathrm{ZnO}$ nanoparticles prepared by sol-gel and sublimation-condensation methods are presented in Fig. 3.

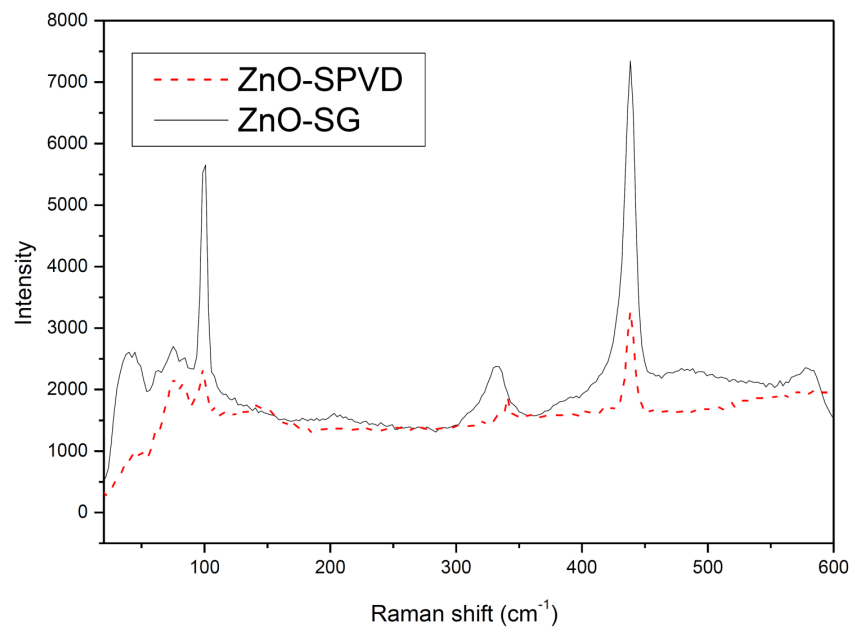

Fig. 3. Raman spectra of ZnO-SPVD and ZnO-SG catalysts.

The Raman spectrum for ZnO-SPVD was found to have peaks at $(98 \pm 1) \mathrm{cm}^{-1},(203 \pm 1) \mathrm{cm}^{-1}$, $(334 \pm 1) \mathrm{cm}^{-1},(438 \pm 1) \mathrm{cm}^{-1}$, and $(570 \pm 1) \mathrm{cm}^{-1}$. As for ZnO-SG, peaks at $(99 \pm 1) \mathrm{cm}^{-1},(203 \pm 1) \mathrm{cm}^{-1}$, $(334 \pm 1) \mathrm{cm}^{-1},(390 \pm 1) \mathrm{cm}^{-1},(438 \pm 1) \mathrm{cm}^{-1}$, $(483 \pm 1) \mathrm{cm}^{-1},(577 \pm 1) \mathrm{cm}^{-1},(581 \pm 1) \mathrm{cm}^{-1}$, and $(661 \pm 1) \mathrm{cm}^{-1}$ were observed. The peak at (438 \pm 1) $\mathrm{cm}^{-1}$ in both samples was $E_{2 \text { (high) }}$ corresponding to the presence of crystalline wurtzite phase in $\mathrm{ZnO}$. These results were consistent with the one obtained from XRD. Moreover, $E_{2 \text { (high) }}$ peak for $\mathrm{ZnO-SG}$ was more intense as compared to $\mathrm{ZnO}-\mathrm{SPVD}$. Since this mode is characteristic of $\mathrm{ZnO}$ Raman spectra and is associated with the motion of oxygen and zinc sublattices in the wurtzite structure of the oxide, as the intensity of this mode increases the degree of crystallinity of $\mathrm{ZnO}$ oxide heightens. That signifies less defects and good cristallinity in the $\mathrm{ZnO}-\mathrm{SG}$ compared to $\mathrm{ZnO}-\mathrm{SPVD}$

The vibration of the zinc sublattice $E_{2 \text { (low) }}$ is one of the most intense modes which peaked at about $98 \mathrm{~cm}^{-1}$. The other weak peaks for both catalysts at $203 \mathrm{~cm}^{-1}$ were due to $2 \mathrm{TA}, 2 E_{2 \text { (low) }}$, and at $(334 \pm 1) \mathrm{cm}^{-1}$ were attributed to difference in frequency of $E_{2(\text { high })}$ and $E_{2(\text { low })}$. This was supposed to be originated from multiplephonon scattering phenomenon [21].

These modes occur due to structural disorders in the host matrix. The peak at $\left(581 \pm 1 \mathrm{~cm}^{-1}\right)$ in $\mathrm{ZnO}-\mathrm{SG}$ was due to $A_{1 \mathrm{~L}}$ mode. The result of Raman analysis provided the information regarding the improved crystallinity (greater crystallites) and structure (less of defects) of $\mathrm{ZnO}$ in $\mathrm{ZnO}-\mathrm{SG}$ comparing with $\mathrm{ZnO}-\mathrm{SPVD}$.

\subsection{Reactor and procedure}

The experiments of the photocatalytic degradation were carried out in a glass reactor using an UV-A lamp $(24 \mathrm{~W})$ that emit at a region of wavelength between $320-400 \mathrm{~nm}$ and an emission peak at $365 \mathrm{~nm}$. The light intensity of the radiation $\left(60 \mathrm{~W} \mathrm{~m}^{-2}\right)$ was measured using a UV radiometer (VLX-3W equipped with a sensor CX-365). The experimental runs were carried out by using the following procedure for the dye: firstly $100 \mathrm{~mL}$ of the solution of the dye was taken into the reactor and a required amount of catalyst was added. Heterogeneous photodegradation and adsorption experiments were performed at room temperature $\left(25 \pm 1^{\circ} \mathrm{C}\right)$ in a glass cell. The irradiated solutions and suspensions were magnetically stirred during whole experiments. The suspensions of dye and catalyst were stirred in the dark for $60 \mathrm{~min}$ before irradiation to establish adsorption/desorption equilibrium. The particles of $\mathrm{ZnO}$ were filtered after irradiation by Millipore filters of $0.2 \mu \mathrm{m}$.

\subsection{Analyses}

The amount of dye adsorbed onto the $\mathrm{ZnO}\left(\mathrm{mg} \mathrm{g}^{-1}\right)$ was calculated using the following relationship [14]:

$$
Q_{\mathrm{ads}}=\frac{\left(C_{o}-C_{t}\right) V}{m},
$$

where $Q_{\text {ads }}$ is the adsorbed quantity at time $t\left(\mathrm{mg} \mathrm{g}^{-1}\right)$, $C_{o}$ is the initial dye concentration $\left(\mathrm{mg} \mathrm{L}^{-1}\right), C_{t}$ is the dye concentration $\left(\mathrm{mg} \mathrm{L}^{-1}\right)$ at the moment $t$ of the process of adsorption, $V$ is the volume of the solution (L), and $m$ is the weight of adsorbent $(\mathrm{g})$.

Degradation extent was calculated using the following equation:

$$
\text { DEG removal }[\%]=\left[\frac{C_{0}-C_{t}}{C_{0}}\right] \times 100
$$

where $C_{0}$ is the initial concentration of dye $\left(\mathrm{mg} \mathrm{L}^{-1}\right)$ and $C_{t}$ is the instant concentration of dye in the sample at time $t\left(\mathrm{mg} \mathrm{L}^{-1}\right)$.

Pseudo-first-order reaction model has been widely and successfully used for the description of photocatalytic degradation of organic pollutants. The removal rates of dye in $\mathrm{UV} / \mathrm{ZnO}(\mathrm{ZnO}-\mathrm{SPVD}$ and $\mathrm{ZnO}-\mathrm{SG}$ ) process is therefore expressed as [14]:

$$
-\frac{\mathrm{d} C_{t}}{\mathrm{~d} t}=\mathrm{k}_{\mathrm{app}} \times C_{t} \Leftrightarrow \ln \left(\frac{C_{0}}{C_{t}}\right)=\mathrm{k}_{\mathrm{app}} \times t,
$$

where $C_{0}$ is the initial concentration of dye, $C_{t}$ the concentration of dye at time $t$ and $\mathrm{k}_{\mathrm{app}}\left(\mathrm{min}^{-1}\right)$ is the pseudo-first-order photocatalytic removal rate constant.

\section{Results and discussion}

\subsection{Adsorption study}

It is likely that adsorption of the dye is an important parameter in determining photocatalytic degradation rate. Adsorption tests in dark were carried out in order to evaluate the equilibrium constants of the adsorption of the dye on the catalyst surface. 
The most common model to describe adsorption process is the isotherm of Langmuir. The Langmuir adsorption isotherm is the most commonly used model to describe adsorption process. The linear transformation of Langmuir adsorption isotherm can be described by the following equations:

$$
\begin{array}{r}
Q_{e}=\frac{Q_{\max } K_{\mathrm{L}} C_{e}}{1+K_{\mathrm{L}} C_{e}}, \\
Q_{e}=\frac{Q_{\max } K_{\mathrm{L}} C_{e}}{1+K_{\mathrm{L}} C_{e}},
\end{array}
$$

where $C_{e}$ is the dye concentration at adsorption equilibrium, $Q_{e}$ is the amount of dye adsorbed on the $\mathrm{ZnO}$ when equilibrium is achieved. $Q_{\max }$ is the theoretical maximum amount of dye adsorbed onto the $\mathrm{ZnO}$ surface, and $K_{\mathrm{L}}$ is the adsorption constant.

The linear transformation of Langmuir GV adsorption on the surface of each of $\mathrm{ZnO}-\mathrm{SG}$ and $\mathrm{ZnO}-\mathrm{SPVD}$ (Eq. (5)) are given in the Fig. 4. From the data obtained, the Langmuir adsorption equilibrium constants $\left(Q_{\max }\right.$ and $\left.K_{\mathrm{L}}\right)$ for both catalysts are given in Table I. Experimental results present a good correlation of the Langmuir model with correlation coefficients $R^{2}$ above 0.99 for both catalysts. This indicates unique adsorption sites, uniform monolayer adsorption, and no interaction between the adsorption sites. It appears that the adsorption coverage is small for both catalysts and the $\mathrm{ZnO}$ produced by the physical method (ZnO-SPVD) exhibits the higher adsorbed quantity. These results can be explained by the differences between the sizes of the two catalyst particles and surface areas. It has been found that the catalyst that has the smallest size of particles and larger surface area has the greatest adsorption capacity [14].

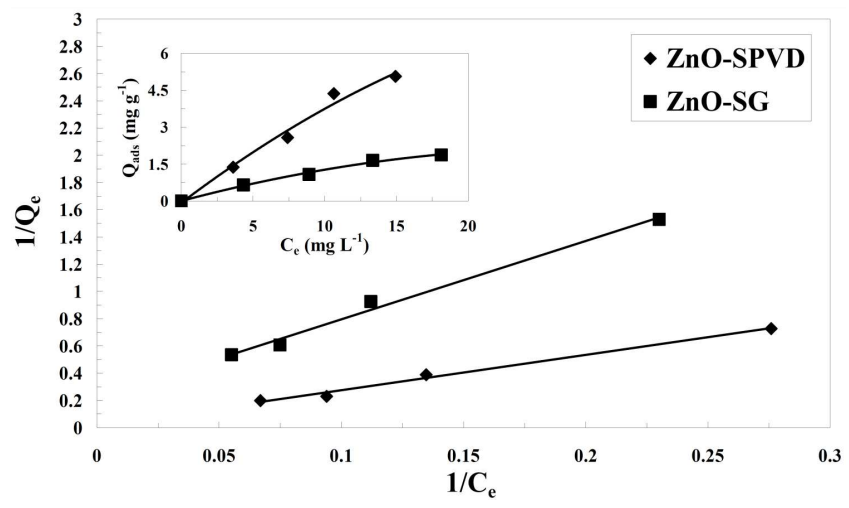

Fig. 4. Langmuir adsorption isotherm of GV on ZnO-SPVD and ZnO-SG: $Q_{e}=f\left(C_{e}\right)$. In the inset: transformation of Langmuir isotherm: $1 / Q_{e}=f\left(1 / C_{e}\right)$ $\left([\right.$ Catalyst $]=1\left[\mathrm{~g} \mathrm{~L}^{-1}\right]$ and $\left.\mathrm{pH}(5.7 \pm 0.2)\right)$.

The adsorption isotherm $Q_{e}=f\left(C_{e}\right)$ for both catalysts are shown in the inset of Fig. 4. The evolution of $Q_{e}$ as function of $C_{e}$ for each of $\mathrm{ZnO}-\mathrm{SG}$ and ZnO-SPVD catalysts, indicates that the Langmuir model is applicable for L-shape type [22]. L-shape type of the isotherm means that there is no strong competition between the solvent and the adsorbate to occupy the adsorbent surface sites.

TABLE I

Langmuir adsorption equilibrium constants of $\mathrm{GV}$ on each of ZnO-SPVD and $\mathrm{ZnO}-\mathrm{SG}$.

\begin{tabular}{l|c|c|c}
\hline \hline & $Q_{\max }\left[\mathrm{mg} \mathrm{g}^{-1}\right]$ & $K_{\mathrm{L}}\left[\mathrm{L} \mathrm{mg}^{-1}\right]$ & $R^{2}$ \\
\hline ZnO-SPVD & 71.43 & 0.0053 & 0.9914 \\
ZnO-SG & 4.58 & 0.0380 & 0.9905
\end{tabular}

\subsection{Comparison of photocatalytic activity of $Z n O-S P V D$ and $Z n O-S G$}

In this study, the comparison between the activities of $\mathrm{ZnO}$ produced by SPVD and SG methods on the GV adsorption and photocatalytic degradation have been investigated at an amount of $1 \mathrm{~g} \mathrm{~L}^{-1}$ of catalyst and a concentration of $10 \mathrm{mg} \mathrm{L}^{-1}$ of $\mathrm{GV}$ at the natural solution $\mathrm{pH}$ of dye $(\mathrm{pH} 5.7 \pm 0.2)$. The results of $\mathrm{GV}$ adsorption on the catalyst surface and GV degradation are shown in Fig. 5. As can be seen, the photodegradation reaction showed a significant degradation of $\mathrm{GV}$ for both catalysts. The degradation of $\mathrm{GV}$ reached $994 \%$ and $708 \%$ in $2 \mathrm{~h}$ during the photodegradation process for each of $\mathrm{ZnO}-\mathrm{SPVD}$ and $\mathrm{ZnO}-\mathrm{SG}$, respectively.

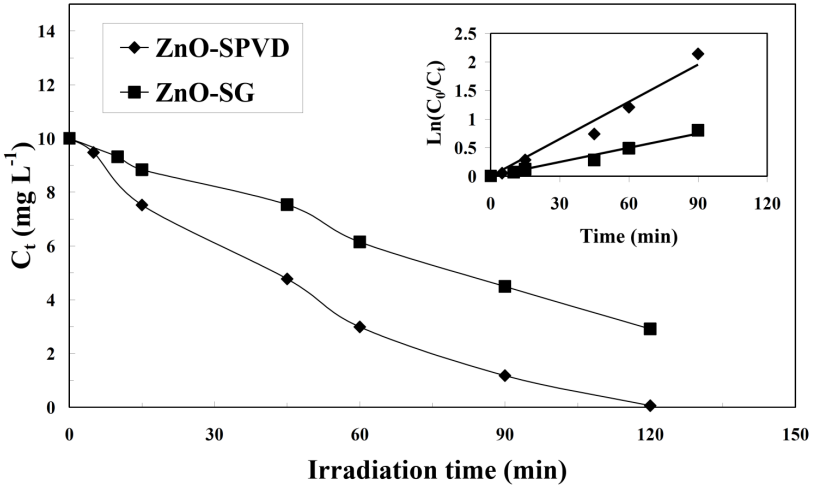

Fig. 5. Kinetics of GV disappearance by photocatalysis process with irradiation time in the presence of each of $\mathrm{ZnO}-\mathrm{SPVD}$ and $\mathrm{ZnO}$-SG. In the inset: Evaluation of pseudo-first order reaction kinetics $\left([\mathrm{GV}]=10\left[\mathrm{mg} \mathrm{L}^{-1}\right]\right.$, $[$ Catalyst $]=1\left[\mathrm{~g} \mathrm{~L}^{-1}\right]$ and $\left.\mathrm{pH}(5.7 \pm 0.2)\right)$.

Inset in the Fig. 5 shows that there is a good linear relationship between $\ln \left(\left[\mathrm{GV}_{0}\right] /[\mathrm{GV}]_{t}\right)$ and irradiation time, which indicates that the GV degradation reaction follows the pseudo-first order kinetics with both catalysts. The values of rate constant of reaction were found to be $2.17 \times 10^{-2} \mathrm{~min}^{-1}\left(\mathrm{R}^{2}=0.991\right)$ and $8.3 \times 10^{-3} \mathrm{~min}^{-1}$ $\left(\mathrm{R}^{2}=0.992\right)$ for $\mathrm{ZnO}-\mathrm{SPVD}$ and $\mathrm{ZnO}-\mathrm{SG}$, respectively. It is shown that the rate constant of GV degradation in the presence of $\mathrm{ZnO}-\mathrm{SPVD}$ is over 2.6 times higher than in the presence of $\mathrm{ZnO}-\mathrm{SG}$, indicating that the catalyst production method greatly affects its photocatalytic 
efficiency. Also, the increase in the ZnO-SPVD efficiency can be attributed to its larger surface area compared to $\mathrm{ZnO}$-SG; a large specific surface area and small crystal size will provide more active sites on the catalyst surface accelerating the production of $\bullet \mathrm{OH}$ radicals that subsequently attack the dye molecules during the photocatalytic system.

\subsection{Effect of initial dye concentration}

The effect of initial dye concentration in water on the photocatalytic process has also been examined. The characteristic dyes concentrations in wastewater from textile industry are in the range from 5 to $30 \mathrm{mg} \mathrm{L}^{-1}$ [23]. Therefore, the reactions of the dye decomposition were carried out in this concentration range. The effect of various initial dyes concentrations on the GV photocatalytic decolorization has been investigated from 5 to $20 \mathrm{mg} \mathrm{L}^{-1}$. The results are shown in Fig. 6.

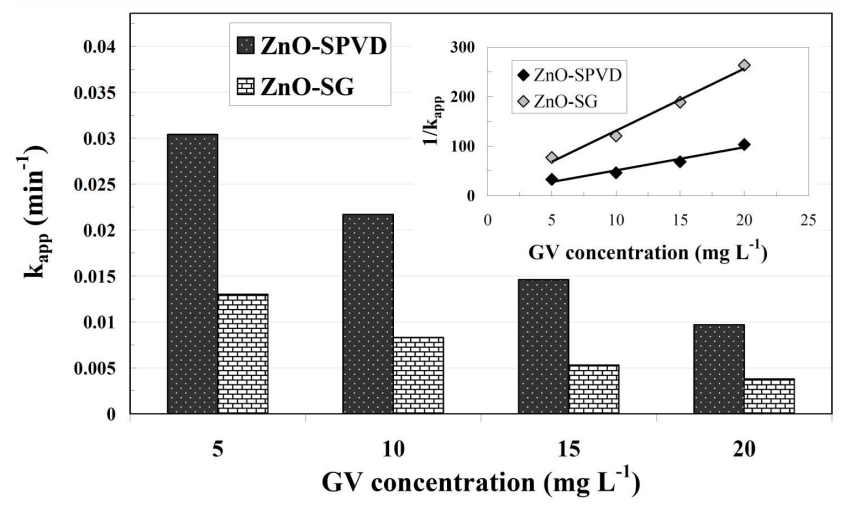

Fig. 6. Effect of initial GV concentration on the photocatalytic degradation. In the insert: transformation of Langmuir-Hinshelwood kinetic: $1 / \mathrm{k}_{\text {app }}=f\left(C_{e}\right)$ ([Catalyst $\left.]=1\left[\mathrm{~g} \mathrm{~L}^{-1}\right], \mathrm{pH}(5.7 \pm 0.2)\right)$.

As seen in in Fig. 6, degradation rate is inversely affected by the dye concentration. This negative effect can be explained by the fact that the increase in dye concentration also decreases the path length of photon entering into the dye solution. However, at high dye concentration a significant amount of UV-light may be absorbed by the dye molecules rather than the catalyst and this may also reduce the catalytic efficiency [24]. The decrease of apparent rate constant for high dyes concentrations can be also attributed to the decrease of active sites due to competition of photoproducts with substrate for the adsorption on the active sites of the $\mathrm{ZnO}$ surface [25] and the increase of degrading molecules towards the number of reactive species photogenerated $\left(\bullet \mathrm{OH}, h^{+}\right)$.

The adsorption and photocatalytic degradation of model pollutants can be well described by the LangmuirHinshelwood $(\mathrm{L}-\mathrm{H})$ kinetic model:

$$
r_{0}=-\frac{\mathrm{d} C}{\mathrm{~d} t}=\frac{k_{r} K_{L-H} C_{e}}{1+K_{L-H} C_{e}}
$$

where $r_{0}\left(\mathrm{mg} \mathrm{L}^{-1} \mathrm{~min}^{-1}\right)$ is the initial rate of disappearance of the dye and $C_{e}\left(\mathrm{mg} \mathrm{L}^{-1}\right)$ represent the amount of dye adsorbed onto the catalyst surface at equilibrium in the dark. $K_{\mathrm{L}-\mathrm{H}}$ represents the equilibrium constant for adsorption of the dye onto $\mathrm{ZnO}$ and $k_{r}$ reflects the limiting rate constant of reaction at maximum coverage under the given experimental conditions. This equation can be used when data demonstrate linearity plotted as follows:

$$
\frac{1}{\mathrm{k}_{\mathrm{app}}}=\frac{1}{k_{r} K_{\mathrm{L}-\mathrm{H}}}+\frac{C_{e}}{k_{r}}
$$

The applicability of $\mathrm{L}-\mathrm{H}$ equation for the dye photodegradation has been confirmed by the linear plot obtained by plotting the $\left(1 / \mathrm{k}_{\mathrm{app}}\right)$ against the $\left(C_{e}\right)$ as shown in the inset in Fig. 6. The values of Langmuir-Hinshelwood equation constants of $\mathrm{GV}$ are listed in Table II. The adsorption equilibrium constant $\left(K_{\mathrm{L}-\mathrm{H}}\right)$ obtained from this linearization is different to the constant obtained from the adsorption isotherm $\left(K_{\mathrm{L}}\right)$ and indicates that adsorption of the dye on the surface of $\mathrm{ZnO}$ particles plays a role in the photocatalytic reaction. The value of the adsorption constant $K_{\mathrm{L}-\mathrm{H}}$ for photocatalytic degradation was about 200 times and 59 times higher than the adsorption constant $K_{\mathrm{L}}$ in the dark for $\mathrm{ZnO}-\mathrm{SPVD}$ and $\mathrm{ZnO}-\mathrm{SG}$, respectively. There have been several studies reporting that $K_{\mathrm{L}-\mathrm{H}}$ could be substantially larger than $K_{\mathrm{L}}[26,27]$. Various explanations have been suggested: (i) the improvement of the adsorption constant may be ascribed to the additional photoadsorption or the fast photocatalytic reaction under UV irradiation [28, 29]; (ii) UV-illumination would change electronic properties of the $\mathrm{ZnO}$ surface and thus the adsorptive sites [26, 30].

TABLE II

Langmuir-Hinshelwood constants of each of ZnO-SPVD and $\mathrm{ZnO}-\mathrm{SG}$

\begin{tabular}{l|c|c|c}
\hline \hline & $\begin{array}{c}K_{r} \\
{\left[\mathrm{mg} \mathrm{L}^{-1} \mathrm{~min}^{-1}\right]}\end{array}$ & $\begin{array}{c}K_{\mathrm{L}-\mathrm{H}} \\
{\left[\mathrm{L} \mathrm{mg}^{-1}\right]}\end{array}$ & $R^{2}$ \\
\hline $\mathrm{ZnO}-S P V D$ & 0.215 & 1.06 & 0.960 \\
$\mathrm{ZnO-SG}$ & 0.445 & 2.25 & 0.987
\end{tabular}

\subsection{Effect of $p H$}

The most important parameter that influences the photocatalytic degradation of dyes is solution $\mathrm{pH}$. Figure 7 presents the variation of the rate constant and the quantity of adsorbed $\mathrm{GV}$ as a function of solution $\mathrm{pH}$ for $\mathrm{ZnO}-\mathrm{SPVD}$ and $\mathrm{ZnO}-\mathrm{SG}$ catalysts.

The results show that photocatalytic degradation of the GV dye is strongly dependent on the $\mathrm{pH}$ of the solution. It was observed that the rate constant of GV degradation reaction increases with the increase of the solution $\mathrm{pH}$ for both catalysts. 


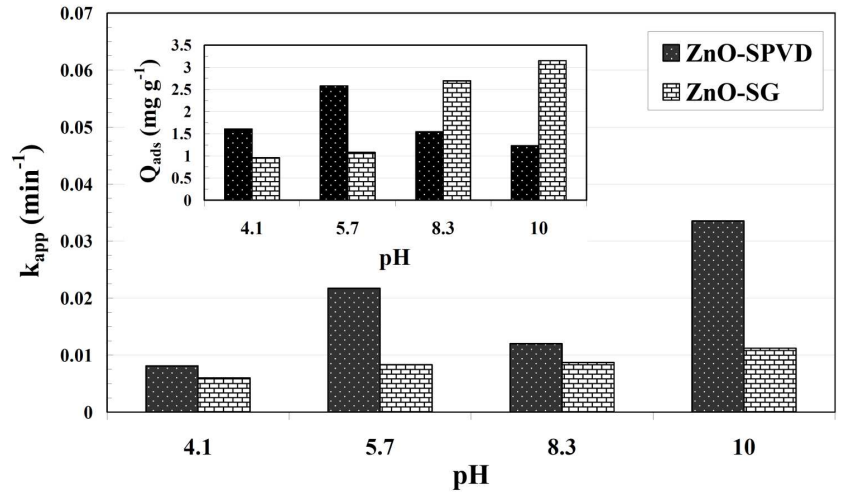

Fig. 7. Effect of $\mathrm{pH}$ on photocatalytic degradation of GV. In the inset: Effect of $\mathrm{pH}$ on the amounts of $\mathrm{GV}$ adsorbed on $\mathrm{ZnO}$ surface $\left([\mathrm{GV}]=10\left[\mathrm{mg} \mathrm{L}^{-1}\right]\right.$ and $[$ Catalyst $\left.]=1\left[\mathrm{~g} \mathrm{~L}^{-1}\right]\right)$.

The photocatalytic removal of GV was observed to be fastest in alkaline $\mathrm{pH}$ for both catalysts and the ZnO-SPVD catalyst presents a higher degradation of GV at alkaline medium ( $\mathrm{pH}$ 10) than the ZnO-SG catalyst. Since the GV adsorption is high at alkaline $\mathrm{pH}$ (inset in Fig. 7), the GV degradation is also efficient at these conditions. This reveals that the dye adsorption on catalyst surface plays a vital role in the dye degradation mechanism.

In addition, when the $\mathrm{pH}$ is slightly alkaline the rate constant of GV degradation increases due to availability of $\mathrm{OH}^{-}$ions in a concentration which is required for increasing the rate of reaction. These $\mathrm{OH}^{-}$ions generate - $\mathrm{OH}$ radicals which are effective in oxidizing species and responsible for the dye photocatalytic degradation.

\subsection{Effect of $\mathrm{H}_{2} \mathrm{O}_{2}$ addition}

The influence of $\mathrm{H}_{2} \mathrm{O}_{2}$ addition on the $\mathrm{GV}$ photocatalytic degradation reaction in the presence of $\mathrm{ZnO}-\mathrm{SPVD}$ and $\mathrm{ZnO}-\mathrm{SG}$ was investigated at an $\mathrm{H}_{2} \mathrm{O}_{2}$ concentration of $10^{-2} \mathrm{~mol} \mathrm{~L}^{-1}$, and the results are shown in Fig. 8 for both catalysts. The amount of dye adsorbed on the catalyst surface in the absence or presence of $\mathrm{H}_{2} \mathrm{O}_{2}$ for both catalysts are shown in the inset in Fig. 8. The degradation rate increased with $\mathrm{H}_{2} \mathrm{O}_{2}$ addition for both catalysts with a ratio of 2.4 times and 6.5 times for $\mathrm{ZnO}-\mathrm{SPVD}$ and $\mathrm{ZnO}-\mathrm{SG}$, respectively. It has been observed that the degradation of $\mathrm{GV}$ proceeds slightly faster in the presence of $\mathrm{ZnO}-\mathrm{SG}$ as compared to $\mathrm{ZnO}-\mathrm{SPVD}$.

On the other hand, the adsorbed quantity of GV decreases after the addition of $\mathrm{H}_{2} \mathrm{O}_{2}$ for the two catalysts. In fact, the hydrogen peroxide molecules can compete with GV molecules on adsorption on the surface of the catalyst resulting in a decrease of GV adsorbed quantity on the surface of catalyst.

These results indicate that structural properties of the catalyst (average crystalline size and surface area) play an important role in the photocatalytic activity of the $\mathrm{ZnO}$ samples.

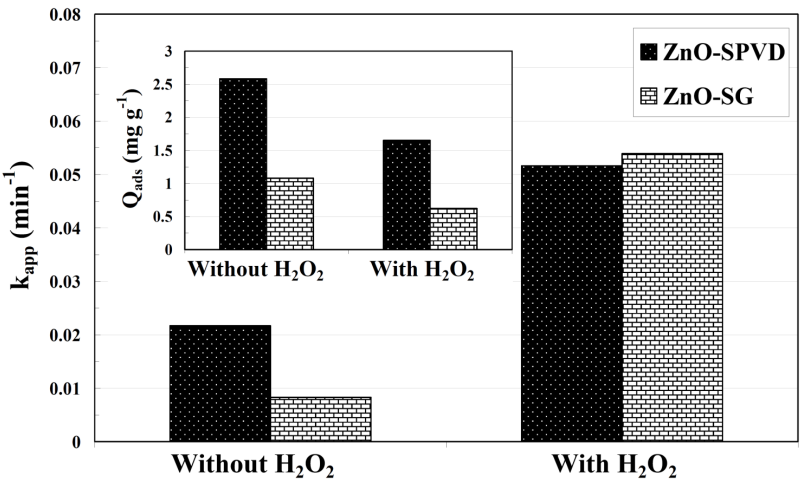

Fig. 8. Effect of $\mathrm{H}_{2} \mathrm{O}_{2}$ addition on the photocatalytic degradation of GV. In the inset: Effect of $\mathrm{H} 2 \mathrm{O} 2$ addition on the amounts of $\mathrm{GV}$ adsorbed on $\mathrm{ZnO}$ surface $\left([\mathrm{GV}]=10\left[\mathrm{mg} \mathrm{L}^{-1}, \quad[\right.\right.$ Catalyst $]=1 \quad\left[\mathrm{~g} \mathrm{~L}^{-1}\right]$ and $\mathrm{pH}(5.7 \pm 0.2))$.

The enhancement of the dye degradation by the addition of $\mathrm{H}_{2} \mathrm{O}_{2}$ is due to the increase in the hydroxyl radical concentrations since it inhibits the $e^{-} \Leftrightarrow h^{+}$recombination [14], according to equations:

$$
\begin{aligned}
& \mathrm{H}_{2} \mathrm{O}_{2}+e^{-} \rightarrow \mathrm{OH}^{-}+\bullet \mathrm{OH}, \\
& \mathrm{H}_{2} \mathrm{O}_{2}+\mathrm{O}_{2}^{\bullet-} \rightarrow \bullet \mathrm{OH}+\mathrm{OH}^{-}+\mathrm{O}_{2} .
\end{aligned}
$$

\subsection{Effect of $\mathrm{HCO}_{3}^{-}$addition}

The influence of $\mathrm{NaHCO}_{3}\left(10^{-2}\right.$ mol L $\left.{ }^{-1}\right)$ at $\mathrm{pH} 8.3$ $\left(\mathrm{HCO}_{3}^{-}\right.$are the predominant species as $\mathrm{pK}_{a}$ $\left.\left(\mathrm{HCO}_{3}^{-} / \mathrm{CO}_{3}^{2-}=10.2\right)\right)$ added to the GV degradation reaction has been studied, and the results are shown in Fig. 9. For both catalysts, the GVdegradation rate constant gradually increased with addition of increasing $\mathrm{HCO}_{3}^{-}$ions in the solution of $\mathrm{GV}$ with a ratio of 2.4 times and 1.6 times for $\mathrm{ZnO}-\mathrm{SPVD}$ and $\mathrm{ZnO}-\mathrm{SG}$, respectively. It was observed that the degradation of GV proceed much more rapidly in the presence of ZnO-SPVD as compared to ZnO-SG. For adsorption results (inset in Fig. 9), the inhibition of the amount of adsorption of $\mathrm{GV}$ on the $\mathrm{ZnO}$ catalysts surface can be attributed to a competitive adsorption on the $\mathrm{ZnO}$ surface between these $\mathrm{HCO}_{3}^{-}$anions and the dye molecules.

The enhancement of GV degradation by addition of $\mathrm{HCO}_{3}^{-}$ions can be attributed on the fact that after the addition of $\mathrm{HCO}_{3}^{-}$ions the $\mathrm{pH}$ of solution increases to alkaline medium, $\mathrm{pH}$ of solution will be around 8.3. Thus, since GV is a cationic dye, it is positively charged in an alkaline medium, whereas, the $\mathrm{ZnO}$ surface will be negatively charged which leads to an electrostatic attraction between dye molecules and $\mathrm{ZnO}$ surface and adsorption could occur, and consequently, the GV degradation rate constant increases [31].

In addition, another reason can explain these results is that after the addition of $\mathrm{HCO}_{3}^{-}$ions, $\mathrm{CO}_{3}^{\bullet-}$ radicals has been formed in the solution, since carbonate radicals can 
attack the dye molecules and enhance the photocatalytic reaction, however, the $\mathrm{CO}_{3}^{\bullet-}$ radicals are less reactive than $\bullet \mathrm{OH}$ radicals [16].

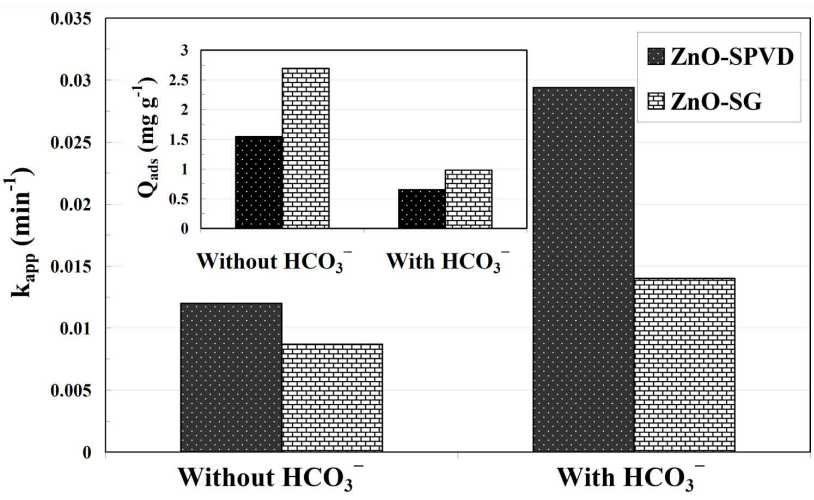

Fig. 9. Effect of $\mathrm{HCO}_{3}^{-}$addition on the photocatalytic degradation of GV. In the inset: Effect of $\mathrm{HCO}_{3}^{-}$addition on the amounts of $\mathrm{GV}$ adsorbed on $\mathrm{ZnO}$ surface $\left([\mathrm{GV}]=10\left[\mathrm{mg} \mathrm{L}^{-1}\right.\right.$, [Catalyst $]=1\left[\mathrm{~g} \mathrm{~L}^{-1}\right]$ and $\left.\mathrm{pH} 8.3\right)$.

\section{Conclusion}

The zinc oxide nano-structure was successfully synthesized by using sublimation-condensation technique (SPVD) and sol-gel method (SG) in nano-size range about $26 \mathrm{~nm}$ and $36 \mathrm{~nm}$, respectively.

$\mathrm{ZnO}$ prepared using SPVD method was more efficient in the photocatalytic degradation of Gentian violet under UV radiation than the material prepared using SG method. These results indicate that the physical characteristics of the catalyst (particles size and specific surface area) play a vital role in the efficiency of the $\mathrm{ZnO}$-based catalysts.

In an attempt to reach higher degradation efficiency of the GV dye solution, the effect of different operational parameters was studied. For both catalysts, the experimental results showed that the degradation rate increases with the decrease of the dye concentration; the degradation rate at alkaline medium was higher than that at natural and acidic one and the presence of $\mathrm{H}_{2} \mathrm{O}_{2}$ and $\mathrm{HCO}_{3}^{-}$ions increased the effectiveness of the photodegradation. In the different conditions studied, a better photocatalytic activity of $\mathrm{ZnO}$ prepared by SPVD method (physical method) was observed compared to $\mathrm{ZnO}$ prepared by sol-gel method (chemical method). It was also observed by adsorption studies that the adsorption of dye is a prerequisite for the degradation process and there is a correlation between adsorption and photocatalytic degradation at different operator conditions.

\section{Acknowledgments}

This work was financially supported by the Ministry of Higher Education and Scientific Research of Algeria.

\section{References}

[1] H.B. Zeng, W.P. Cai, P.S. Liu, X.X. Xu, H.J. Zhou, C. Klingshirn, H. Kalt, Acs Nano 2, 1661 (2008).

[2] H. Zhang, J.B. Wu, C.X. Zhai, N. Du, X.Y. Ma, D. Yang, Nanotechnol. 18, 455604 (2007).

[3] S. Bhatia, N.Verma', Mater. Res. Bull. 95, 468 (2017).

[4] B.O. Chin, Y.N. Law, M.A. Wahab, Renew. Sust. Energ. Rev. 81, 536 (2018).

[5] D. Rajamanickam, M. Shanthi, Arab. J. Chem. 9, S1858 (2016).

[6] J.R. Torres-Hernández, E. Ramírez-Morales, L. Rojas-Blanco, J. Pantoja Enriquez, G. Oskam, F. Paraguay-Delgado, B. Escobar-Morales, M. Acosta-Alejandro, L.L.Díaz-Flores, G. PérezHernández, Mater. Sci. Semicon. Proc. 37, 87 (2015).

[7] G.C. Hadjipanayis, R.W. Siegel, Nanophase Materials: Synthesis-Properties-Applications, Series E: Applied Science, KluwerAcademic Publishers, Dordrecht 1994, p. 260|.

[8] N. Lemée, C. Duboudieu, G. Delabouglise, J.P. Sénateur, F. Laroudie, J. Cryst. Growth 235, 347 (2002).

[9] K.P. Surendran, A. Wu, P.M. Vilarinho, V.M. Ferreira, Chem. Mater. 20, 4260 (2008).

[10] F. Maxim, P. Ferreira, P.M. Vilarinho, I. Reaney, Cryst. Growth Design 8, 3309 (2008)

[11] K.V. Saravanan, M.G. Krishna, K.C.J. Raju, A.K. Bhatnagar, J. Mater. Sci. 42, 1149 (2007).

[12] E. Neyens, J. Baeyens, J. Hazar. Mater. 98, 33 (2003).

[13] S. Parsons, Advanced Oxidation Processes for Water and Wastewater Treatment, IWA Publishing, Cornwall (UK) 2004.

[14] N. Bouanimba, R. Zouaghi, N. Laid, T. Sehili, Desalination 275, 224 (2011).

[15] H.S. Rai, M.S. Bhattacharya, J. Singh, T.K. Bansal, P. Vats, U.C. Banerjee., Crit. Rev. Env. Sci. Technol. 35, 219 (2005).

[16] N. Bouanimba, N. Laid, R. Zouaghi, T. Sehili, Int. J. Chem. React. Eng. , 20170014 (2017).

[17] Y. Liu, J. Lin, M. Chen, L. Song, Food and Chem. Toxicol. 58, 264 (2013).

[18] H. Benhebal, M. Chaib, M. Crine, A. Léonard, S. Lambert, Chiang Mai J. Sci. 42, 585 (2016).

[19] A. Rouanet, H. Solmon, G. Pichelin, C. Roucau, F. Sibieude, C. Monty, Nanostruct. Mater. 6, 283 (1995).

[20] T.L. Thompson, J.T. Yates. S, Chem. Rev. 106 4428 (2006).

[21] D. Das, P. Mondal, RSC Adv. 4, 35735 (2014).

[22] C.H. Giles, A.P. D'Silva, I.A. Easton, J. Colloid Interface Sci. 47, 766 (1974).

[23] M. Vautier, C. Guillard, J.M. Herrmann, J. Catal 201, 46 (2001).

[24] A. Mills, R.H Davis, D. Worsley, Chem Soc Rev 22, 417 (1993). 
[25] N. Serpone, E. Pelizzetti, Photocatalysis: Fundamentals and Application, Wiley Interscience, New York 1989.

[26] E. Vulliet, J.M. Chevelon, C. Guillard, J.M. Hermann, Photochem. Photobiol 159, 71 (2003).

[27] J. Cunningham, G. Al-Sayyed, S. Srijaranai, Adsorption of Model Pollutants onto $\mathrm{TiO}_{2}$ Particles in Relation to Photoremediation of Contamined Water in: Aquatic and Surface Photochemistry, Ch. 22, Eds. G. Helz, R.D. Zepp, D. Crosby, Lewis Publs, CRC Press, Boca Raton (FL) 1994, p. 317.
[28] S. Qourzal, M. Tamimi, A. Assabbane, Y. Ait-Ichou, Colloid. Interf. Sci.286, 621 (2005).

[29] Y. Meng, X. Huang, Y. Wu, X. Wang, Y. Qian, Environ. Pollut 117, 307 (2002).

[30] M. Sleiman, D. Vildozo, C. Ferronato, J.M. Chovelon, Appl. Catal. B: Environ 77, 1 (2007).

[31] N. Laid, N. Bouanimba, R. Zouaghi, T. Sehili, Desalin. Water Treat. 57, 1935 (2016). 